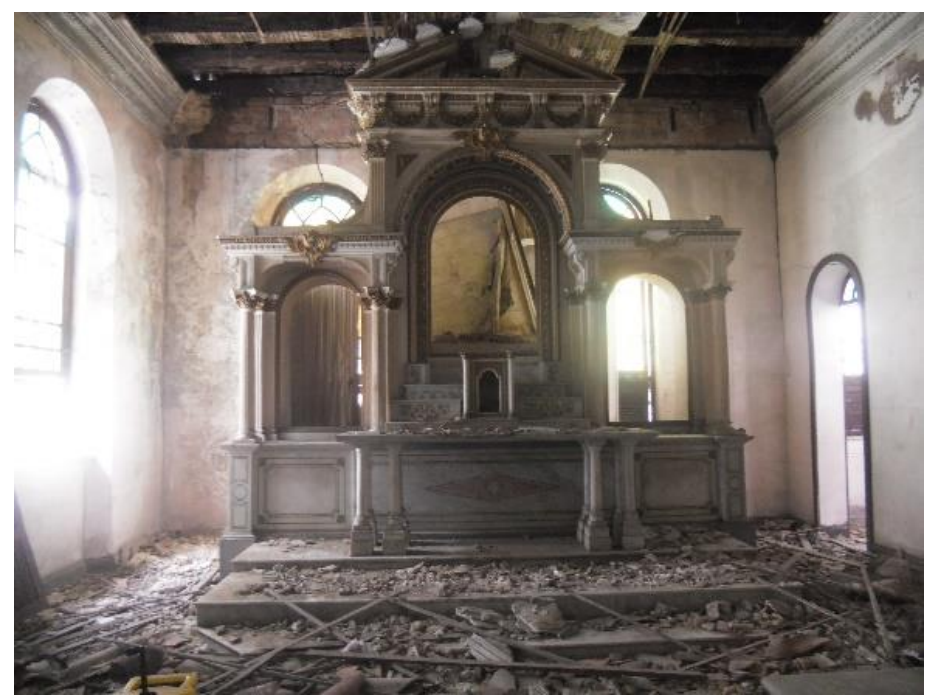

\title{
Ruínas, duração e patrimonialidade
}

Ruins, duration and heritage

Cybelle Salvador Miranda ${ }^{1}$

\section{Resumo:}

A construção do conceito de patrimônio na cultura contemporânea nos convida a uma reflexão sobre os contextos de recepção dos bens a serem preservados. Neste panorama, as ruínas assumem significados distintos, acentuando a disparidade entre as noções de duração e o papel do patrimônio edificado para a constituição das singularidades locais. Considerando as ruínas como fenômenos característicos da modernidade, arquiteturas da Belém histórica dialogam com outros artefatos no Brasil e em Portugal para fazer pensar no sentido antropológico da duração.

Palavras-chave: patrimônio, memória, ruínas.

\section{Abstract:}

The construction of the concept of heritage in contemporary culture invites us to reflect on the contexts of reception of goods to be preserved. In this panorama, the ruins take on different meanings, emphasizing the disparity between the notions of duration and the role of heritage buildings for the establishment of local singularities. Considering ruins as modernity's phenomenon, architectures of the historical city of Belém dialogue with others artefacts in Brazil and in Portugal, in order to make think in the anthropological sense of duration.

Keywords: heritage; memory; ruins.

\footnotetext{
${ }^{1}$ Doutora em Antropologia, Professora da Faculdade de Arquitetura e Urbanismo e do Programa de Pósgraduação em Arquitetura e Urbanismo, coordena o Laboratório de Memória e Patrimônio Cultural (LAMEMO), na Universidade Federal do Pará. Endereço Institucional: Cidade Universitária Prof. José da Silveira Netto, Atelier de Arquitetura, Guamá, Belém, Pará, Brasil. E-mail: cybelle1974@ hotmail.com
} 


\section{A construção do conceito de patrimônio}

Desenvolvida no campo da História e da Antropologia, a História do Patrimônio se fragmentou em diversos objetos de investigação, dos museus aos monumentos, passando pelo patrimônio imaterial. Assim, a História do Patrimônio é "a história da maneira como uma sociedade constrói seu patrimônio" (POULOT, 2009, p. 12).

O Patrimônio é resultado da dialética conservação x destruição. A atitude patrimonial tem dois aspectos: a assimilação do passado, com a metamorfose dos vestígios e restos, e a relação de estranheza com a presença de testemunhas do tempo remoto na atualidade. A Arquitetura não é uma expectadora da história, e sim um ente no qual as várias etapas se impregnam, se juntam ou se excluem. O homem vive o presente construindo o amanhã, em uma maré de constante adaptação e superação. A tempestade que conduz o anjo de Benjamin, Na Tese IX de "Sobre o conceito de História", é uma alegoria para o dilema do homem contemporâneo: voltado para os escombros do passado, é inexoravelmente conduzido para o futuro.

$\mathrm{Na}$ passagem ao século XXI, o patrimônio deve contribuir para revelar a identidade de cada um como reflexo e comunicação com o outro: seja o passado perdido ou o local etnográfico. São vários os imaginários do patrimônio ocidental. Assim, percebe-se a criação de ruínas a partir de edifícios históricos em Belém, Pará, que permitem um diálogo com outros artefatos no Brasil e em Portugal para fazer pensar no sentido antropológico do patrimônio e da duração.

A gênese do patrimônio evoca as leituras eruditas: a era da erudição no século XVIII apoiava-se na preocupação com as fontes: o método moderno da pesquisa histórica distingue as fontes originais das de segunda mão. No século XVIII, a reflexão baseava-se no diálogo entre fontes literárias e fontes figuradas. Para construir a definição do patrimônio impunha-se estabelecer a autenticidade e o valor dos monumentos, bem como a conservação do patrimônio ligava-se a formação do público ou a prosperidade do país. Já o patrimônio "legal" surgiu no século XIX, tendo destaque na França (POULOT, 2009).

No final do XVIII até 1830 a patrimonialização passa de uma representação monumental do saber e da memória para abranger todos os elementos da cultura material do passado. A partir da Revolução francesa, diferentes processos - invenção do museu, do monumento histórico, reconfiguração da arqueologia e sucesso do romance histórico - inventaram um patrimônio associado à nova coletividade nacional.

A destruição do antigo regime e de seus signos teve sua retomada mais tarde, 
nostalgicamente, através das ruínas que sugerem um trabalho de esquecimento e supressão. O conceito de monumento no século XVIII oscila entre "qualquer construção que serve para conservar a memória do tempo e de seu fabricante ou daquele para quem havia sido erguido, tal como um arco de triunfo, um mausoléu ou uma pirâmide" (D’Aviler, Cours d' architecture ...1761) e "as testemunhas irrepreensíveis da história" (Kersaint, 1791) (apud POULOT, 2009, p. 45).

A relação entre território e estética do século XVI ao XVIII era vista em antiguidades e outros guias de monumentos urbanos. Os guias serviram para criar uma cultura parisiense, baseada no valor das obras de arte. Os ingleses do Grand tour eram os mais interessados nesses itinerários didático-culturais, o que gerava dividendos aos locais que preservassem suas antiguidades. Em decorrência dessa demanda, na cidade de Nimes foi criada em 1683 a Académie Royale, dedicada aos estudos dos monumentos antigos.

Em Roma, o interesse turístico tornou-se preocupação oficial. "No âmago da estética neoclássica, verificou-se o aparecimento de uma cultura e de uma política da conservação, no exato momento em que um grande número de obras de arte era espalhado através da Europa" (POULOT, 2009, p. 58). Verifica-se a ligação íntima “entre a nova representação da inscrição da memória cultural e o programa de histórias patrióticas inéditas" - caso dos etruscos, na Itália.

Há uma mudança na concepção arqueológica, com novas preocupações éticas e políticas, relacionando as descobertas ao local do sítio e às fontes escritas. Criou-se a partir de Herculano e Pompéia uma arqueologia "vesuviana". Surgiam também museus de cópias. O século XVIII, sob a égide das viagens à Itália e do surgimento da Estética como disciplina (teoria da arte), forjou a ideia de que a arte serve à educação, através de seus exemplos mais belos.

Segundo Poulot, quando hoje pensamos em ampliar sempre o patrimônio, o século XVIII "fatigado com as trivialidades da história", desejava uma depuração negociada. “O esquecimento não é, de modo algum, ignorância. Até mesmo esquecidas, as antigas noções de sociedade e de ordem devem ser não tanto inculcadas, mas reanimadas. A história é uma reminiscência” (FOURET e OZOUF apud POULOT, 2009, p. 80).

A associação entre erudição e pertencimento a uma comunidade moral, no XVIII, fazia com que apenas pessoas inseridas em certos círculos sociais tivessem acesso ao conhecimento de sua história. Hoje, o patrimônio ocupa posição privilegiada 
nas configurações da legitimidade cultural, nas reflexões sobre a identidade e nas políticas de vínculo social: a legitimidade tem a ver com a antropologia jurídica e política de longa duração; a identidade se baseia no Estado-nação do século XIX e as políticas de vínculo social fizeram a herança passar de preocupação das elites para tornar-se compromisso coletivo.

\section{A 'Era da Cultura' sob o Signo do Patrimônio}

Nos tempos atuais, não cansamos de evocar 'patrimônios' a serem conservados e transmitidos, quer sejam relativos à apreciação estética do cotidiano, a manutenção do legado arquitetural, a preservação das habilidades artesanais e dos mestres. Porém, Poulot (2009) crê que o próprio patrimônio determina as condições de sua abordagem, comunicação e controle.

A história do patrimônio divide-se em: história-memória do patrimônio nacional, destacando os arautos mais notáveis; ou as associações e movimentos envolvidos com a conservação. "O patrimônio não é o passado, já que sua finalidade consiste em certificar a identidade e afirmar valores, além da celebração de sentimentos, se necessário, contra a verdade histórica" (POULOT, 2009, p. 12). Daí porque não se deve recorrer a ele como testemunho, e sim valorizá-lo como repositório de valor afetivo.

Arantes (1998) detecta que, na sociedade contemporânea, tudo virou 'cultura', e o 'patrimonialismo' tornou-se a política máxima desta nova Era, que significa a transformação de todas as faces da cultura em patrimônio, não só no sentido da memória social, mas principalmente como gerador de lucro. Numa perspectiva marxista, estas políticas são interpretadas como compensatórias em relação aos grupos excluídos social e economicamente, que passam a ter visibilidade cultural. No âmbito da economia, a acumulação de 'capital simbólico' impulsiona a geração de lucro no mercado das instituições públicas e privadas que administram a 'cultura'.

Poulot define o termo 'patrimonialidade' "para designar a modalidade sensível de uma experiência do passado, articulada com uma organização do saber identificação, atribuição - capaz de autentificá-lo" (2009, p. 28). Observa que nos dias de hoje confunde-se patrimonialidade com patrimonialização, propondo uma abordagem renovada do fenômeno, amparado na antropologia histórica, aplicada ao caso francês.

A construção da patrimonialidade em Belém torna-se problemática por ser ela uma cidade há muito ligada às tradições europeias, porém, inserida no contexto da 
natureza 'virgem', e com anseios de modernidade. Inserida na Amazônia, a cidade capital que fora, no século XVIII, lugar de construções monumentais, e nos finais do século XIX era conhecida como a 'Paris nos trópicos', hoje reinventa o imaginário mítico de terra selvagem e exótica, em busca dos investimentos no turismo ecológico. Nesse contexto, o passado é também considerado como uma ligação desconfortável com a tradição, sinônimo de atraso.

No Centro histórico de Belém, a ausência de uso social, se bem que muito menos acentuado do que em outras cidades brasileiras, relega ao abandono - às vezes calculado à espera da destruição - muitas edificações de séculos passados, que guardam vestígios materiais do cotidiano em sua aparente simplicidade.

Entender o patrimônio como conceito ocidental e ainda recentemente incorporado na cultural brasileira faz-se necessário para pensar a situação em que se encontra boa parte de nosso casario sujeito aos estatutos da preservação. O desprezo às frações arruinadas como a capela da Santa Casa de Misericórdia do Pará, perdida em meio ao frenético movimento hospitalar - ou as casas tomadas por vegetação, e ainda as fachadas-máscara que delimitam apenas um vazio interior fazendo as vezes de muro são várias as modalidades de ruínas, desprovidas de atributos de valor (Figuras 1 e 2).

Com o desmonte dos Estados nacionais, a iniciativa privada torna-se "parceira" de todos os eventos culturais. O processo de elevação no prestígio das áreas da cidade que sofreram requalificação, como o caso do Pelourinho em Salvador, alia a proposta de inclusão das identidades locais ao fluxo turístico internacional. Este processo inicia-se no pós-guerra, com a reação à modernização e como esforço para recuperar a memória e os valores locais das cidades destruídas pela guerra na Europa. Porém, assume nos anos 60 do século XX a configuração dominantemente mercadológica, com a transformação do capitalismo fordista em capitalismo financeiro. Inicia-se a Era da desconstrução e da colagem (ARANTES, 1998).

Figuras 1 e 2: Interior da antiga capela da Santa Casa e Fachadas máscara na Rua Dr. Assis

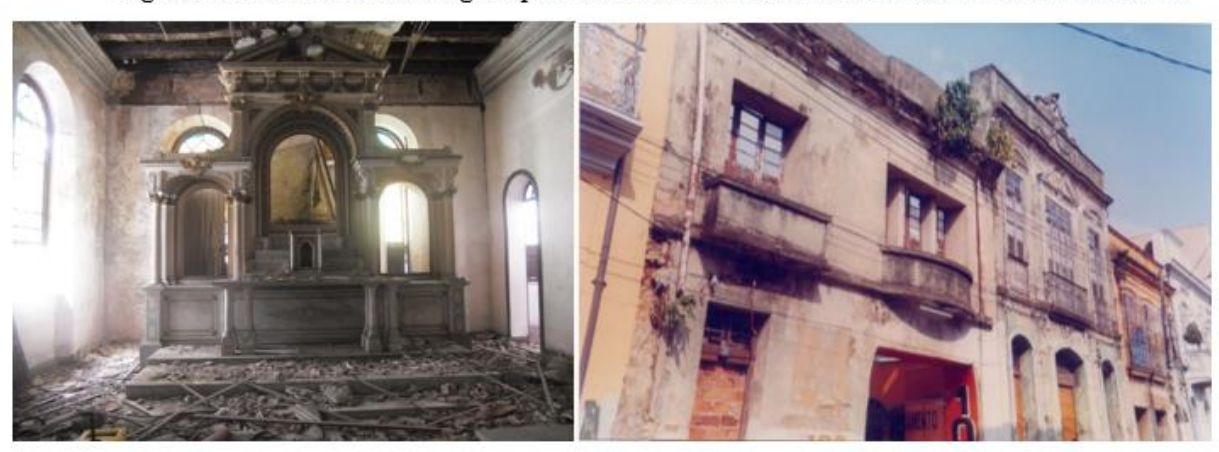

Fotos: Cybelle Miranda, 2014; 2004. 
A "Era da Cultura" é parte das feições pós-modernistas das sociedades contemporâneas, é a superação do modernismo pelo pós-modernismo inclusivista, que faz a releitura do passado associando-o às diversas configurações das sociedades regionalizadas, impondo-se a elas na forma da reelaboração de seus elementos pela cultura de mercado dominante.

André Chastel observa que o termo 'patrimônio' possui hoje um sentido global e vago, cuja aparição data de apenas dois séculos. Da versão inicial de patrimônio como ente simbólico ligado à perpetuidade dos objetos sagrados essenciais à comunidade: o Palácio de Tróia, a Virgem negra de Chartres e os tesouros pertencentes à Igreja, hoje presenciamos a dessacralização geral das formas sociais que nos leva a pensar o patrimônio como "cultural” (CHASTEL, 1997).

Para Poulot, a necessidade humana de viver a duração é um dos determinantes do patrimônio. Sua seleção é dada pelas práticas eruditas, bem como sua apropriação pelo público depende dos catálogos e itinerários propostos. O termo patrimônio significa inicialmente "bens de herança" e depois tornar-se-á alvo das identidades.

Sempre como iniciativa europeia, a noção de patrimônio e monumento histórico se implantou mundialmente, como forma de garantir às sociedades a sobrevivência dos referenciais do passado. A mundialização dos valores e das referências ocidentais contribui para a expansão das práticas patrimoniais, a partir da Conferência Geral da UNESCO de 1972, atribuindo a alguns monumentos e sítios históricos o título 'patrimônio mundial', o que desafia a visão local de algumas culturas.

Enfim, o grande projecto de democratização do saber, herdado do Iluminismo e reanimado pela vontade moderna de erradicar as diferenças e os privilégios do usufruto dos valores intelectuais e artísticos, a par do desenvolvimento da sociedade de lazer e do seu correlativo, o turismo cultural, dito de massas, estão na origem da expansão talvez mais significativa, a do público dos monumentos históricos (CHOAY, 2000, p. 184).

Parte da França a difusão do termo cultura, que integra os projetos de "Casas da Cultura" presentes em todo o mundo, inclusive nos municípios brasileiros mais longínquos, sob vários títulos: cultura minoritária, cultura popular, etc. Os museus consagram-nas antes dos monumentos - "[a] cultura perde o seu carácter de realização pessoal, torna-se empresa e, rapidamente, indústria” (BENJAMIN, 1989, p. 185). O valor de uso torna-se econômico, graças à “engenharia cultural”, vasta empresa pública 
e privada a serviço da qual atuam animadores, comunicadores, mediadores culturais, os quais desejam multiplicar indefinidamente o número de visitantes.

Segundo Passeron à cultura podem ser atribuídas três significações distintas: a cultura-estilo, a cultura declarativa e a cultura corpus.

A primeira designa o conjunto dos modelos de representação e das práticas que orientam a organização das formas da vida social. A segunda, a de uma cultura como comportamento declarativo, corresponde a reivindicação de uma identidade de grupo [...]. Por último, a cultura como corpus de obras valorizadas define o universo simbólico de um grupo social, ao privilegiar um reduzido número de objetos culturais como outros tantos de seus símbolos favoritos. (PASSERON apud POULOT, 2009, p. 19-20.)

Choay (2000) aponta alguns problemas ou efeitos perversos da massificação no processo de preservação de espaços históricos, dentre os quais: a permanente conservação e restauro requerido frente às multidões que danificam e desgastam os sítios históricos, a artificialidade nas intervenções como a iluminação noturna que suprime o peso da arquitetura, os comentários e ilustrações presentes nas exposições que, ao invés de instruir cultiva a passividade do público.

Outra consequência desse processo é a transformação dos monumentos em 'shopping centers da cultura', nos quais as intervenções, a pretexto de preservar o aspecto histórico de certos centros antigos, aplicam estereótipos do lazer urbano como cafés ao ar livre, tendas de artesanato, galerias de arte, redes de lanchonetes internacionais, restaurantes, desfigurando os aspectos peculiares destes lugares, banalizando-os. Com isso,

o condicionamento sofrido pelo patrimônio urbano histórico tendo em vista o seu consumo cultural, bem como a sua disputa pelo mercado imobiliário de prestígio, tende a excluir dele as populações locais ou não privilegiadas $\mathrm{e}$, com elas, as suas atividades tradicionais $\mathrm{e}$ modestamente quotidianas (CHOAY, 2000, p. 197).

Na intervenção denominada Complexo Feliz Lusitânia, em Belém, observa-se que a restauração do casario adjacente à Igreja de Santo Alexandre retirou os antigos comerciantes que nestes pontos realizavam suas atividades e lá instalaram loja de artesanato, sorveteria, casa de recepções, repartição estadual de patrimônio cultural e o Museu do Círio, estratégia a qual não obteve rentabilidade, de modo que os espaços foram paulatinamente ocupados por repartições do Governo estadual. Cabe, portanto, discutir a pertinência de processos de 'revitalização' que desagregam valores tradicionais a pretexto de restaurar não as construções e objetos, mas uma perspectiva idealizada do espaço-patrimônio. 
Tanto as culturas tradicionais quanto as formas do passado servem hoje apenas como repertório de detalhes para compor um mosaico aleatório presente em todas as manifestações da cultura atual. Os centros históricos e os monumentos passam de patrimônios da sociedade a meros cenários de consumo da 'cultura' e de divertimento. Jameson cita o exemplo do turista que, fotografando a cena urbana a transforma graficamente em imagem material, apossando-se dela (1995, p. 15).

$\mathrm{Na} 2^{\mathrm{a}}$ metade do século $\mathrm{XX}$ emergiram ideias de culturas múltiplas que poderiam fortalecer diversas identidades. Hoje o patrimônio é instrumento de desenvolvimento local (turismo, saber e lazer). Após a queda do bloco socialista emerge uma patrimonialização nostálgica (temos como exemplo o filme Adeus, Lênin).

Poulot destaca que "a razão patrimonial pode fornecer uma moldura para as iniciativas de restituição de bens culturais ou para as decisões de anistia em relação a pilhagens do passado - por exemplo, nas relações de uma metrópole com suas antigas colônias" (2009, p. 201). Por outro lado, “a atualidade impactante da patrimonialização parece ter impedido o questionamento a respeito da construção dessa forma de obrigação relativamente à presença material do passado". Assim, a recusa ou contestação à patrimonialização é estigmatizada com o termo ‘vândalo’ (2009, p. 202).

A carência de critérios na definição dos objetos de preservação é assim detectada por Poulot: “o patrimônio institucionalizado não passa, em vários aspectos, de uma câmera de gravação dos movimentos aleatórios brownianos, cujo contorno é desenhado a partir de manifestações de admiração e reconhecimento, de compras e revendas, além de acúmulo de bens e de rejeições" (2009, p. 20). Seu corpus se fixa nos guias, relatos de viagens, cartas, jornais, catálogos, em função das reproduções em circulação, da importância das citações a seu respeito. Surge a Arqueologia, que dá lugar a diversas enunciações dos valores locais, seja em forma de tradicionalismos ou de revivals.

A novidade da década de 1980 deve-se à ideia de que "a familiaridade com o patrimônio pode ser legitimamente incluída no número dos direitos humanos [...]. Cada cidadão tem o direito de dedicar-se a uma pesquisa de paternidade cultural que lhe permitirá conhecer-se de um modo que não se restrinja ao deserto das cidades-dormitórios, nem às tecnologias de evasão". (QUERRIEN apud POULOT, 2009. p. 228)

Os valores sociais substituem os da história da arte, num culto da democracia. Em 1979 a Carta de Burra introduz a noção de "significação cultural" que atribui às comunidades de interpretação o direito de identificar o patrimônio. 


\section{Ruínas, memória e esquecimento}

Nunca foi tão concreta como hoje a metáfora benjaminiana 'escavar e lembrar'. Aliás, junto com 'O Narrador', 'Escavar e lembrar' é a síntese premonitória da pósmodernidade arruinada. Cada vez busca-se mais fundo, para compensar a superficialidade no campo social. O passado é uma meta a ser atingida, a incompletude da ruína apresenta-se como única explicação para um presente sem conceitos e sem valores. As escavações arqueológicas trazem à tona objetos que, expostos em vitrines iluminadas, nada mais são que "torsos na galeria do colecionador". Por mais que os recursos museográficos tentem explicar sua existência, há apenas experiência.

A figura do narrador bem poderia estar aí, contando aos visitantes, como se netos fossem, as glórias do passado, as histórias fantásticas, as pequenas passagens de uma trajetória individual anônima.

A lógica do valor de troca das mercadorias norteia as concepções de Benjamin, influindo na tese das fantasmagorias, quando o citadino busca no passado a pré-história da sociedade sem classes. ${ }^{2}$ Fantasmagorias são evocações do passado, retomadas em acontecimentos do presente como mito. Os mitos da Modernidade aparecem nas cidades, palco das massas e da mercadoria. O edifício representa a ambiguidade do passado que convive com o presente: o novo subjaz o antigo, envelhecendo a cada ciclo da novidade, portanto o novo é o sempre igual e o eterno retorno de modelos do passado.

As tensões entre consciência do presente e nostalgia do passado se expressam na Arquitetura, objeto que testemunha as épocas da história e permite ao citadino viajar no tempo: as utopias de Boullée e sua Arquitetura de formas puras, descontextualizadas, fruto da imaginação do artista, assim como os falanstérios de Fourier, construídos como galerias feitas para a moradia dos trabalhadores, representavam o sonho do futuro revestido em modelos do passado. O percurso dos séculos se cristaliza na cidade, e a preservação do patrimônio edificado conduz à leitura de um tempo-espaço que não volta mais, mas que emerge no imaginário coletivo como a busca do ideal, da felicidade.

Interessa a Benjamin a história da Modernidade, e não a historiografia de seus acontecimentos que, ignorando a constante metamorfose do passado à luz do presente, leva a fantasmagorias que se expressam na ideologia e no sensível (arquitetura, moda,

\footnotetext{
${ }^{2}$ O Passagen-Werk é uma história das origens do movimento histórico presente, o capitalista. Marx argumentou que, até a plena realização do novo potencial do industrialismo, toda história era pré-história, dominada pelas 'leis naturais' do capitalismo.
} 
urbanismo). O homem fica prisioneiro do mito, e sua visão do novo é no fundo uma reiteração obsessiva do sempre-igual, o tempo do inferno. Na ânsia de mostrar o novo, a sociedade moderna transforma tudo em novidade efêmera, que logo se torna antiguidade, numa linha unidirecional: "a sensação de tudo-novo, de tudo feito moderno, é uma forma de futuro tão onírico quanto o eterno retorno do mesmo" (BENJAMIN, 1989, p. 563).

Para Benjamin, a história deve ser lida pela perspectiva dos vencidos, o que rompe a linearidade da história tradicional pela utopia que descobre o mito. "A barbárie se esconde no próprio conceito da cultura enquanto tesouro de valores, e mesmo quando ela não é vista como independente do processo produtivo em que surgiu, é vista como independente do processo produtivo em que sobrevive" (ROUANET, 1987, p. 44). A leitura dos objetos do passado deve ser feita, portanto, à luz das concepções do presente, compreendendo o cenário em que se inseriam, mas reconduzindo-os às nossas visões atuais.

No ambiente contemporâneo, as ruínas surgem em vários contextos, no provisório, no abandono dos casarões antigos, no uso proposital dos fragmentos na construção de novos panoramas, como ocorre nos edifícios que preservam uma parte do casarão antigo existente no terreno como atrativo a mais, tornando mais nobre e exclusivo o empreendimento imobiliário. A colagem inaugurada pelos modernistas passa a ser a linha mestra nas 'revitalizações', obras que modernizam o aspecto degradado de sítios abandonados pelo crescimento urbano: a Praça Frei Caetano Brandão, parte do sítio da fundação da cidade de Belém, ganha 'roupa nova' pois as edificações assumem o ocre tido como característica do colonial brasileiro, as calçadas cimentadas são revestidas por ardósia, os jardins tradicionais de tantos anos recebem as plantas da moda - as palmeiras - típicas das costas de praia do Nordeste ou do Caribe. São bastante eficazes, pois, ao contrário das mangueiras com suas copas fartas, não atrapalham a visibilidade dos monumentos e da paisagem.

O muro é opaco, sendo substituído pelas grades transparentes no século XIX. Hoje os muros são peças fundamentais nos condomínios. As cidades antigas e medievais tinham as muralhas como demarcação importante de território, que servia ao sentido de proteção e abrigo, enquanto nos pórticos dava-se o fluxo, as entradas triunfais, a passagem simbólica ao desconhecido. A relação pórtico-muro em Roma permanece através de algumas das entradas pertencentes à maior urbe do mundo antigo, hoje feitas ruína que balizam a espacialização dos tempos na cidade. Nos subterrâneos 
do Palácio do Louvre igualmente sobrevivem restos da muralha da primitiva cidade romana.

A transparência é acentuada nas obras de refuncionalização de ruínas, como no projeto de Paulo Mendes da Rocha para a Pinacoteca de São Paulo (Figura 3). Perde-se a materialidade da edificação, que passa a simbolizar a eliminação dos limites físicos, ao mesmo tempo em que assinala a supressão da profundidade no mundo contemporâneo.

Figura 3: Pinacoteca de São Paulo

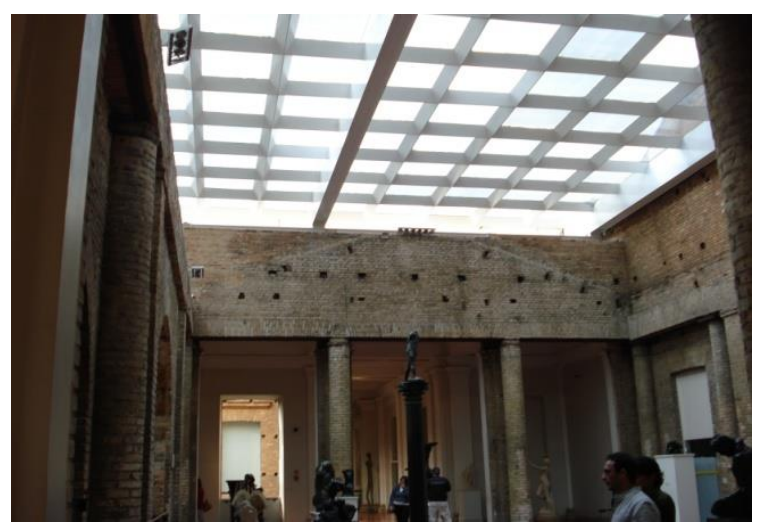

Foto: Cybelle Miranda. 2009

Ecos do passado, as ruínas hoje são signos da "pós-modernidade". O inacabado, o provisório se junta aos fragmentos de outros tempos, desnudam-se as estruturas na busca das origens, das técnicas primitivas. Nas muralhas de pedra do Forte lêem-se simbolicamente as mãos dos índios tupinambás que ajudaram a construí-las, mas na realidade o Forte que os índios produziram, materialmente não existe mais (Figura 4).

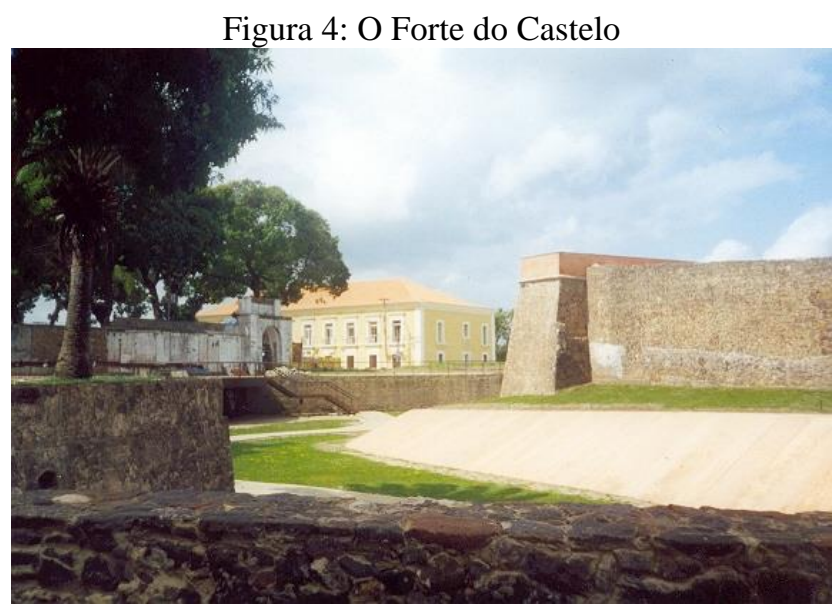

Foto: Cybelle Miranda. 2002 
Segundo Simmel, a arquitetura tem como característica o equilíbrio entre a matéria que pesa e resiste positivamente à pressão e a espiritualidade formadora que se vê destruída no momento em que o edifício cai em ruínas. $\mathrm{O}$ encanto destas deve-se à ação do tempo (natureza) sobre a obra humana, de modo que o abandono das construções torna o homem cúmplice da natureza. As ruínas são um lugar de vida, de onde a vida se retirou. Por isso o Forte emerge como ruína no contexto atual: as intervenções o transformaram num espaço desértico (SIMMEL, 1984).

Chastel corrobora a interpretação de Simmel, ressaltando que

[a] destruição e a ruína do inútil é a lei da natureza. A cultura intervém para anular ou retardar esta lei, em nome de imperativos mais elevados. Mas então o que será do imenso 'parque' de capelas e igrejas, pouco a pouco privadas do suporte natural que é a presença dos fiéis. Essenciais à paisagem, elas não devem desaparecer. Uma solução de reuso deve ser encontrada. Será a hora de lembrar que em toda sociedade o patrimônio se reconhece no fato de que sua perda constitui um sacrifício e que sua conservação supõe sacrifícios? É a lei de toda sacralidade (CHASTEL, 1997, p. 1460-1461).

Ironicamente, o autor atenta para o fato de que a conservação de bens materiais se baseia nas necessidades humanas de manter um bem além de sua função original, preservando-o da ruína, o que em si impõe dificuldades para a vida moderna, mas que é plenamente justificada pelo caráter 'sagrado', ou simbólico, que tais bens representam para os seres sociais. Este pensamento, que está no cerne da discussão filosófica da preservação do patrimônio, nem sequer é referido nos textos que tratam sobre o patrimônio no Brasil, o que, sem dúvida, é uma lacuna expressiva, tornando as ações de preservação/restauração como autoexplicativas, não admitindo a dúvida e o questionamento como meios de ampliar dialeticamente o debate.

Para uma política de reabilitação eficaz, faz-se necessário evidenciar duas funções da arquitetura: prática e simbólica. Um recorrente equívoco dos técnicos é embasar as justificativas de preservação em fatores estético-históricos, que apresentam pouca relevância para a população. Os detentores de bens de interesse a preservação necessitam de boas condições de estrutura urbana, bons serviços públicos, bem como se deve ressaltar o vínculo afetivo do proprietário com o bem.

A Arqueologia conduz a abertura de enormes trincheiras: Portugal inteira descobre suas origens romanas. Seja em estações de Metrô, no Claustro da Sé Velha, no Castelo de São Jorge ou no Criptopórtico romano de Coimbra (Figura 5). 
Figura 5: Criptopórtico em Coimbra

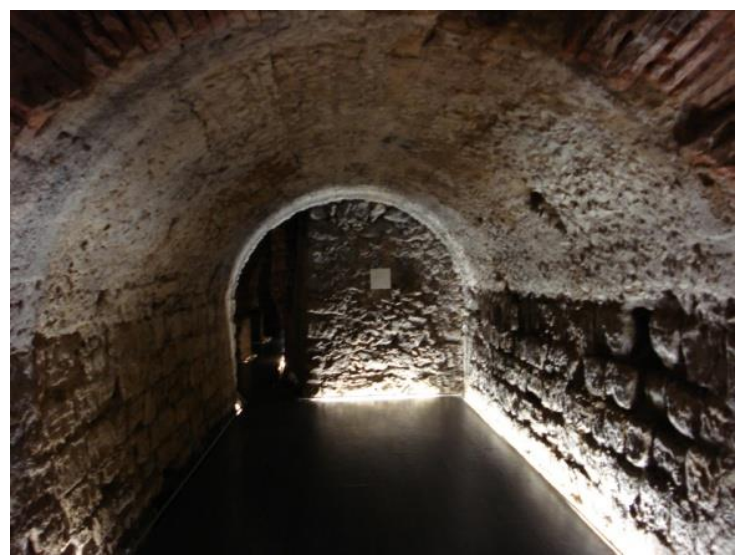

Fonte: Cybelle Miranda. 2009

O Criptopórtico é hoje o exemplo mais impressionante de como trazer à tona algo que estava enterrado pelo passado, um labirinto de galerias feito para sustentar o Fórum, foi desentulhado e leva os visitantes a uma expedição pela magnificência da antiga Aeminium. Em Lisboa, o Núcleo Museológico do Castelo nos conduz a um passeio milenar entre o século VII a. C. e o Terremoto de 1755 (Figuras 6 e 7). Criado em 2008, enfatiza o espólio da Alcaçova islâmica, na qual lisboetas e portugueses de todas as partes vasculham a sua origem moura, imergindo num melancólico saudosismo. O espaço cenário inclui o recurso musical - um homem vestido à moda medieval toca um flautim, que transporta os visitantes ao momento mítico - o passado.

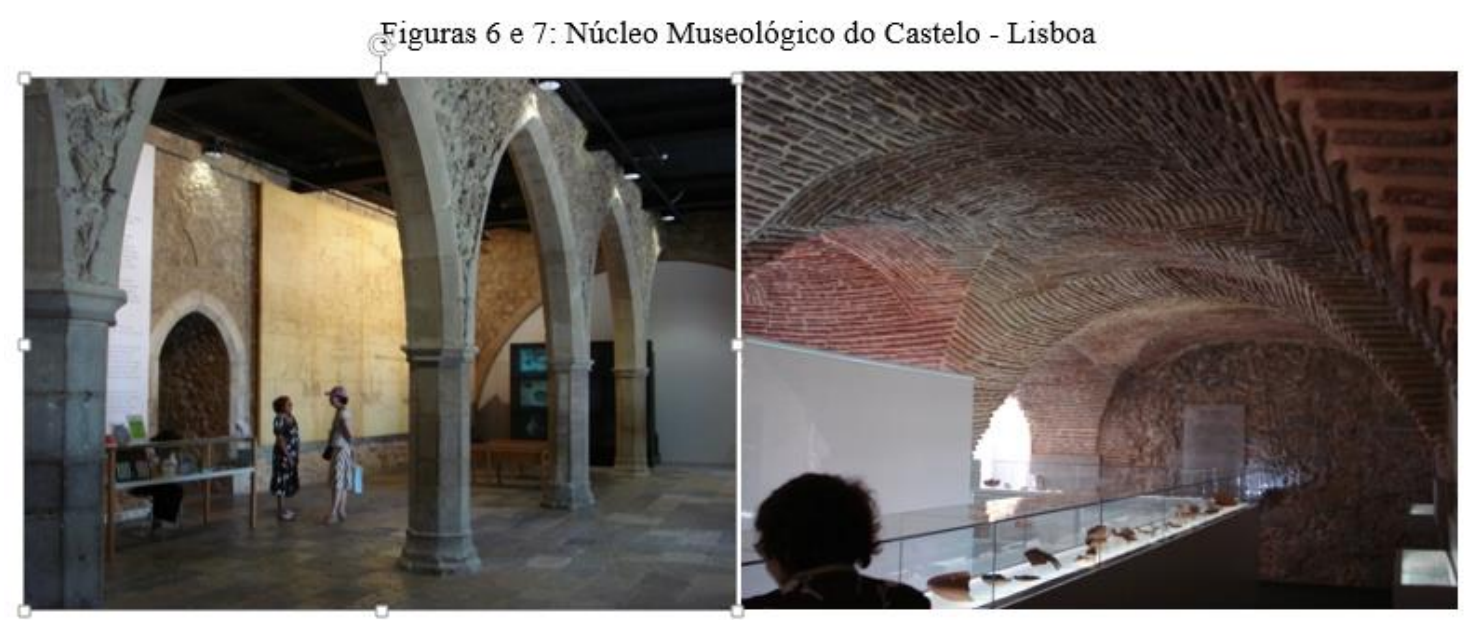

Fotos: Ronaldo Marques de Carvalho. 2009

Os vestígios de um grande acidente - o terremoto de 1755 em Lisboa transformam-se em um museu a céu aberto, que foi o que restou da Igreja do Carmo. As paredes ainda em pé contrastam com o azul do céu, conduzindo, entre placas, túmulos e estátuas, um percurso que culmina com o que restou da capela-mor, espaço fechado no qual se expõe relíquias da antiguidade ao século XIX. Criado em 1864, o museu expõe 
peças de antigos edifícios arruinados e da própria igreja. O cenário intrigante cativa pela integração com o ambiente, bem como pela 'casual' ordenação dos materiais aí expostos, de modo que o visitante sente como se estivesse percorrendo os escombros de um acidente que acabara de ocorrer. (Figuras 8 e 9).

Figuras 8 e 9: Museu Arqueológico do Carmo - Lisboa
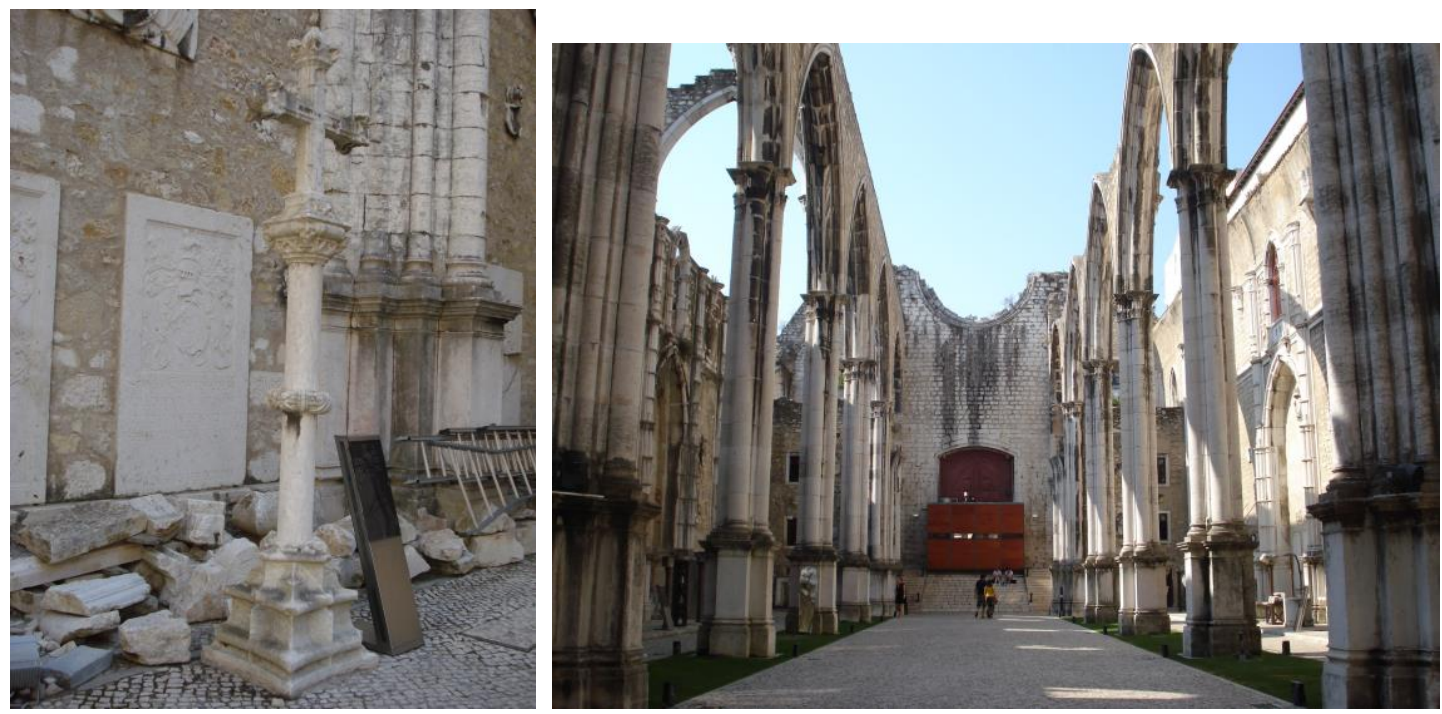

Fotos: Cybelle Miranda, 2011

Cabe então a pergunta: Diante da hipertrofia da memória, como pensar o esquecimento?

A memória para os gregos é ao mesmo tempo "a que faz recordar e a que faz esquecer os males, a rememoração do passado implicando no esquecimento do tempo presente" (CHAVES, s.d, p. 2). Segundo Nietzsche "todo agir requer esquecimento" e "há um grau de insônia, de ruminação, de sentido histórico, no qual o vivente chega a sofrer dano e por fim se arruína, seja ele um homem ou um povo ou uma civilização" (NIETZSCHE, 1997, p. 56). Na perspectiva nietzchiana, só o que não cessa de causar dor é gravado na memória, o que nos põe diante de uma encruzilhada: o que se quer lembrar não está suficientemente marcado e o que está gravado na memória impede a ação.

Por isso, o passado deve ser selecionado criticamente, e a tensão entre o que deve ser lembrado e o que deve ser esquecido é benéfica para a construção do presente significante. A hipertrofia da memória também é nociva, pois conduz à histeria. Pensar a tradição e pensar a Modernidade é para Benjamin um processo dialético, é uma construção e não uma reconstrução. O passado não existe enquanto tal, mas enquanto 
fragmentos que devem ser lidos no presente, e a função do historiador crítico é fazer ecoar a voz dos oprimidos de ontem.

A construção da memória cultural exige uma estrutura apropriada para o estabelecimento de conexões e formação de redes, não se relaciona com as referências externas e apoia-se em narrativas e mitos estruturados, que permitem que esta seja propagada para gerações futuras. O filtro da memória é importante para a construção das identidades culturais, assimilação de momentos marcantes de vitória e derrota, esquecendo as vergonhas e humilhações (ASSMANN, 2003).

Escrever a história dos vencidos necessita de elementos que não constam nos livros oficiais. Por isso Benjamin usa uma teoria da memória e da experiência, uma experiência coletiva que permita religar o passado submerso com o presente. As ressurreições do passado coletivo são o trabalho do historiador materialista. O trabalho da memória não é fluido, mas muitas vezes interrompido por resistências dadas por momentos de sofrimento e derrota. Nesta atividade da rememoração ocorre uma mistura de tempos, em que o presente é privilegiado por trazer à tona lembranças as quais, vistas em relação a este, podem ser objeto de transformação (CHAVES, 2003).

O relato do narrador, do contador de histórias é o objeto central da possibilidade de várias leituras do passado, que não se dá de forma acabada e definitiva, e que assimila a perspectiva dos vários grupos sociais. $\mathrm{O}$ acontecimento lembrado é infinito, pois é apenas a chave para tudo o que veio antes e depois. O tempo para Benjamin é o do futuro do pretérito, aquele do que poderia ter sido, aquilo que não se realizou, restando apenas ruínas (GAGNEBIN, 1993).

E a memória é o meio do vivido, que deve ser vasculhada como quem escava, em busca das várias camadas de tempo que estão imersas nesse espaço. Os produtos deste trabalho são "as imagens que, desprendidas de todas as conexões mais primitivas, ficam como preciosidades nos sóbrios aposentos de nosso entendimento tardio - como torsos na galeria do colecionador" (BENJAMIN, 1987, p. 239). Benjamin ensina o caminho que deve trilhar aquele que deseja conhecer o passado: assinalar no presente o local do achado antigo e indicar as camadas das quais esses achados se originam, desde a superfície.

Portanto, para ler os fragmentos da história expressos nas formas materiais dos monumentos históricos é preciso ultrapassar a leitura mítica e fazer o papel do historiador crítico: ouvir as vozes esquecidas, através dos pequenos indícios, das imagens apagadas na memória daqueles que vivem o espaço. Recolher os traços das 
atividades cotidianas serve para fazer ecoar esse passado da experiência coletiva, muito distante das coleções particulares organizadas nos museus, composta por fragmentos descontextualizados, iluminados feericamente pelo foco da história oficial.

Benjamin alerta para a memória-arqueologia: o passado deve ser sondado como quem escava, revolvendo várias vezes o mesmo fato, e partir da trajetória do inventariante, de modo que memória e sujeito sejam um todo. "E se ilude, privando-se do melhor, quem só faz o inventário dos achados e não sabe assinalar no terreno de hoje o lugar no qual é conservado o antigo" (BENJAMIN, 1987, p. 239). Nessa trilha, as ruínas não são conjuntos de achados, mas traços que se mesclam em nossa própria vida - a genealogia. Só faz sentido o passado se ele puder falar de nós e para nós.

Segundo Riegl (2006), não existe um valor artístico eterno, mas somente um valor relativo, e, portanto, o culto do 'valor de antiguidade' seria mais inclusivo, pois destacaria uma obra da forma que ela tinha sido constituída e modificada pelo tempo, respeitando-a integralmente como documento histórico.

A lei do movimento cíclico, que produz a verdadeira satisfação estética produzida por monumentos antigos, exige que esses não sejam fixados pela conservação, mas submissos ao fluxo incessante da mudança. Deve ser evitada a intervenção arbitrária da mão do homem sobre o estado do monumento, pois "não é necessário adicionar nem substituir o que foi alterado ao longo dos anos sob a ação das forças naturais, tampouco suprimir os acréscimos que alteram a forma original" (RIEGL, 2006, p. 73).

Existem diferentes temporalidades no monumento: a ancianidade inscrita pelo desgaste, os acidentes e as ruínas; a historicidade relativista sustentada por uma construção intelectual e a intencionalidade original, fiel à tradição.

O espectador de um monumento é remetido a um sentido antropológico da duração, através da leitura no presente. Na história cultural valoriza-se a legibilidade das vidas sucessivas do monumento, as escolhas voluntárias de interpretação e a complexidade das formas de transmissão.

\section{Considerações Finais}

A Arquitetura de épocas passadas materializa a memória social, e serve de referente às evocações do passado de uma comunidade. Assim, as casas construídas nos séculos anteriores têm função social que ultrapassa sua concretude, assumindo papel relevante para a identidade de um lugar. O estado de abandono em que se encontram 
resulta de vários fatores, dentre os quais as aceleradas mudanças por que passaram as cidades entre os séculos XIX e XX, resultando em alterações significativas de comportamentos dos indivíduos, especialmente no contexto familiar. Hoje, as famílias encontram-se reduzidas, e a moradia ocupa espaços menores, que exigem menos gastos.

Portanto, para garantir a sobrevivência das arquiteturas da Belém antiga, é preciso que o poder público proveja de infraestrutura o espaço onde estas edificações se situam, especialmente no Centro Histórico, onde o calçamento, serviços de iluminação, acesso a transportes, equipamentos e mobiliário urbanos são precários, além de atentar para a formação de mão de obra técnica especializada para o reparo destes imóveis, cuja tecnologia deve ser alvo de pesquisas científicas, a fim de propor soluções de restauração compatíveis com as técnicas primitivas. Muitas vezes os proprietários substituem elementos singulares de época pela carência de profissionais capacitados para a recuperação de calhas, condutores, paredes de taipa, entre outros.

Deve-se considerar que os edifícios que testemunham a passagem do tempo na cidade de Belém, Pará, ao serem restaurados, passem a ter uma função definida, uma vez que o bem patrimonial não cumpre sua função social sem que esteja em uso, além do que toda edificação desocupada se deteriora com maior rapidez.

Por sua vez, ao serem escolhidos novos usos para estes imóveis, na impossibilidade de se manter o uso primitivo, estes devem ser compatíveis com a preservação do valor estético e histórico do bem. Todas as vezes em que for possível preservar o bem em seu uso original, este é preferível a qualquer outro, mesmo que seja de caráter cultural, uma vez que o uso impregna o imóvel de valores materiais e imateriais.

Urge pensar a duração como um fenômeno dialético em que a preservação e o apagamento são faces da dinâmica das cidades, dinâmica esta que, na contemporaneidade, torna-se mais aguda à medida que nos defrontamos com a cultura digital que impacta na produção do ambiente construído. Diante dos desafios postos para a definição e redefinição dos bens patrimoniais em sua relação com a sociedade, urge pensar as ruínas como criação de sentidos diversos nas quais se inscreve os posicionamentos da sociedade contemporânea perante o passado. 


\section{Referências}

ARANTES, Otília. Urbanismo em fim de linha e outros estudos sobre o colapso da modernização arquitetônica. São Paulo: Edusp, 1998.

ASSMANN, Aleida. A gramática da memória coletiva. Humboldt, 86, Bonn, GoetheInstitut Inter Nationes, p. 2-4, 2003.

BENJAMIN, Walter. A obra de arte na era de sua Reprodutibilidade técnica. Obras Escolhidas. Magia e técnica, arte e política: ensaios sobre Literatura e História da Cultura. v. 1. São Paulo: Brasiliense, 1985.

BENJAMIN, Walter. A tarefa do tradutor. Escritos sobre mito e linguagem (19151921). São Paulo: Duas cidades;Ed. 34. 2011.

BENJAMIN, Walter. Escavar e Lembrar. Obras Escolhidas. v. 2. São Paulo: Brasiliense, 1987.

Cerf, 1989.

. Paris Capitale du XIX ${ }^{\mathrm{e}}$ Siècle - le livre des passages. Paris: Éditions du

CHASTEL, André. La notion de patrimoine In: NORA, Pierre. Les Lieux de Mémoire. Paris:Gallimard,1997. v.1.

CHAVES, Ernani. Memória, Esquecimento e a constituição histórica da Filosofia. s.d. p. 2. (Texto de Aula da Disciplina Memória e Esquecimento, 2003)

CHAVES, Ernani. História, memória e esquecimento. No limiar do moderno: estudos sobre Friedrich Nietzsche e Walter Benjamin. Belém: Paka-Tatu, 2003.

CHOAY, Françoise. A alegoria do Patrimônio. Lisboa: Edições 70, 2000.

GAGNEBIN, Jeanne-Marie. Walter Benjamin - os cacos da história. São Paulo, Brasiliense, 1993. (Coleção Tudo é História)

JAMESON, Fredric. As marcas do visível. Rio de Janeiro: Graal, 1995.

NIETZSCHE, Friedrich. Genealogia da Moral. São Paulo: Companhia das Letras, 1997.

POULOT, Dominique. Uma história do patrimônio no Ocidente. São Paulo: Estação Liberdade, 2009.

ROUANET, Sergio Paulo. As Razões do Iluminismo. São Paulo: Companhia das Letras, 1987.

RIEGL, Aloïs. O Culto moderno dos monumentos sua essência e sua gênese. Trad. Elaine Ribeiro Peixoto e Albertina Vicentine. Goiânia: Ed. da UCG, 2006.

SIMMEL, Jorge. Las Ruínas In: Cultura Femenina y otros ensayos. Madrid: Revista de Occidente, 1984.

Data de Recebimento: 01/09/2016

Data de Aprovação: 09/11/2016 


\section{Para citar essa obra:}

MIRANDA, C. S. Ruínas, duração e patrimonialidade. In: RUA [online]. nº 22 . Volume 2, p. 407 - 424 - ISSN 1413-2109/2179-9911 - Novembro/2016. Consultada no Portal Labeurb - Revista do Laboratório de Estudos Urbanos do Núcleo de Desenvolvimento da Criatividade.

http://www.labeurb.unicamp.br/rua/

Capa: MIRANDA, C. S. Figura 1. 2014

\section{Laboratório de Estudos Urbanos - LABEURB}

Núcleo de Desenvolvimento da Criatividade - NUDECRI

Universidade Estadual de Campinas - UNICAMP

http://www.labeurb.unicamp.br/

Endereço:

LABEURB - LABORATÓRIO DE ESTUDOS URBANOS

UNICAMP/COCEN / NUDECRI

CAIXA POSTAL 6166

Campinas/SP - Brasil

CEP 13083-892

Fone/ Fax: (19) 3521-7900

Contato: http://www.labeurb.unicamp.br/contato 